\title{
VALUATION DAS STARTUPS
}

Pedro Santos ${ }^{1}$

Luis Renato Junqueira ${ }^{1}$

Paula Karina Salume ${ }^{1}$

${ }^{1}$ Pontifícia Universidade Católica de Minas Gerais - PUC Minas 


\section{VALUATION DAS STARTUPS}

\section{RESUMO}

O aumento das startups tem chamado a atenção de estudiosos com relação à adequação dos métodos tradicionais de análise de uma empresa. Neste trabalho, foi abordado o conceito de valuation para as startups. A pesquisa tem como objetivo estabelecer os pressupostos utilizados nos modelos de valuation para as startups, considerando as particularidades do seu modelo de negócio. A coleta de dados foi realizada por meio de entrevistas com empreendedores de Belo Horizonte. Os resultados encontrados apontam que os entrevistados encontraram dificuldades na elaboração do valuation e que para a obtenção de um valor justo para a startup é necessária a compreensão da fase da startup, o modelo do negócio, o tipo de produto ou serviço ofertado, a tecnologia envolvida, a equipe de execução e, por fim, identificar o modelo de valuation mais adequado. Portanto, percebe-se o quão importante é o conhecimento dos diversos métodos de valuation para precificar as startups.

Palavras-chave: Startup. Valuation. Inovação. Modelo de negócio.

\section{INTRODUÇÃO}

Com a grande revolução tecnológica vivenciada nos últimos tempos, com a dinamicidade do mercado e o com o aumento acelerado de novos produtos e serviços, as startups estão ganhando destaque no mercado em diversos segmentos. Elas apostam, justamente, nas oportunidades de inovação em produtos e serviços que satisfaçam de maneira prática, eficaz e tecnológica os desejos e necessidades dos consumidores.

Tais empresas surgem a partir de uma ideia inovadora e ganham forma na medida em que o criador encontra meios para financiar seu projeto ou investidores que se interessem pela ideia. Como toda empresa, se faz necessário um determinado capital para o seu bom funcionamento e crescimento. A startup apresenta uma estrutura flexível, de modo que, a sua adequação ao mercado seja favorecida. Dessa forma, quando algum produto ou serviço apresenta rejeição perante ao público alvo, rapidamente a startup se reposiciona e direciona seus esforços para adapta-lo.

Portanto, para conseguir os devidos recursos para o seu financiamento, a startup, normalmente, passa pelo processo de valuation, que mede o valor da empresa. Existem diversas maneiras para realizar esse procedimento, contudo as startups apresentam características bem distintas, por conseguinte, não é uma tarefa fácil para encontrar o modelo mais adequado.

$\mathrm{O}$ valuation tem como objetivo mensurar o quão relevante é o negócio da empresa e assim identificar o seu valor justo. Essa técnica é comumente utilizada em empresas tradicionais, entretanto, estas apresentam características diferentes em comparação com as startups, logo, os modelos de valuation devem ser adaptados de acordo com as especificidades de cada empreendimento com a finalidade de apresentar um resultado mais preciso.

Startups são firmas que possuem grande potencial inovador e tecnológico e se diferenciam das demais empresas tradicionais devido à sua dinamicidade que visa agilizar determinado processo proposto por ela.

Devido à grande revolução tecnológica presenciada nos últimos anos, vários processos comumente executados por empresas tradicionais caíram em desuso e, como consequência, esse

DOI: $10.14211 /$ xi-egepe-118040 
novo modelo de negócio tem ganhado força competitiva no mercado, apostando na flexibilidade, inovação, tecnologia e praticidade. Embora não sejam características exclusivas, é perceptível o destaque nesses aspectos.

Uma das principais dificuldades encontradas por estes novos empreendimentos relaciona-se à escassez de recursos para o seu financiamento, à competição entre empresas pioneiras e à menor produtividade por parte das startups (DULLIUS; SCHAEFFER, 2016).

Normalmente, quando as startups conseguem agradar a um público, elas atingem um crescimento exponencial. Para suportar essa evolução, na maioria das vezes, a startup necessita de um significativo volume de recursos financeiros, os quais são geralmente aportados por investidores externos. Nesse momento, torna-se crucial a determinação do valor da companhia.

Considerando que as startups possuem características bastante específicas, essa pesquisa pretende responder à seguinte questão: quais devem ser os pressupostos dos modelos de valuation para as startups, considerando as suas particularidades em relação aos negócios tradicionais?

As startups já conquistaram seu espaço em meio às demais organizações convencionais, sendo perceptível a sua colaboração para o desenvolvimento de novos produtos e serviços tecnológicos. A partir de uma estrutura inovadora, podem-se desenvolver empresas que vão revolucionar em seu ramo de atuação, devido ao avanço tecnológico e por meio das plataformas digitais que possibilitam a acessibilidade, de maneira ágil e prática, dos diversificados tipos de consumidores do serviço ou produto ofertado.

Além da natureza tecnológica, tais empresas contribuem com a sociedade por meio de oferta de serviços que facilitam o cotidiano das pessoas e conjuntamente geram empregos mais valorizados, que exigem mais qualificação da mão de obra.

Com o crescente número de startups com uma visão de um novo modelo de negócios, uma técnica de valuation adequada é parte fundamental para que possam se posicionar dentro do mercado e assim atrair investidores, parceiros e clientes.

O processo de valuation é importante para encontrar o preço justo da startup, possibilitando que a mesma se posicione no mercado, saiba seu valor, tenha poder de negociação e até mesmo direcione seus esforços à obtenção do investimento adequado e necessário para sua potencialização.

A partir do valuation das startups e do seu melhor posicionamento no mercado, é possível que haja a ampliação da quantidade de investidores, em função da clareza de informação sobre os valores das mesmas, possibilitando, assim, o seu desenvolvimento, ganho de competitividade no mercado que atua, bem como, a abertura da oportunidade para outras startups de grande valor tecnológico receberem investimentos.

Portanto, o objetivo geral desta pesquisa é estabelecer os pressupostos utilizados nos modelos de valuation para as startups, considerando as particularidades do seu modelo de negócio.

Além desta introdução, o artigo foi dividido em mais quatro seções. Na segunda seção, nominada "Referencial Teórico", buscou-se discutir, sinteticamente, os principais conceitos que envolvem as startups e modelos de valuation. Na próxima seção foram apresentados os procedimentos metodológicos utilizados na pesquisa. Na quarta seção estão expostos e discutidos os resultados da pesquisa. Por último, na quinta seção, estão as considerações finais do trabalho contendo as principais conclusões da pesquisa, além das limitações do estudo e das sugestões para novos trabalhos. 


\section{REFERENCIAL TEÓRICO}

\subsection{Startups}

As novas empresas que possuem como fundamento a tecnologia e inovação são denominadas startups. São organizações que atuam em um cenário impreciso, contudo com grandes possibilidades de um crescimento exponencial em um curto espaço de tempo. (ASSOCIAÇÃO BRASILEIRA DE STARTUPS, 2014). Tais empresas surgem a partir de uma ideia inovadora e, posteriormente, é elaborado o projeto de funcionamento e gestão. As startups são empresas bem distintas em relação às empresas tradicionais, sendo seu modelo de negócio flexível, podendo ser mudado por diversas vezes e sem um grande processo burocrático. Assim, traçam seus objetivos e vão ao mercado testar se o pressuposto produto/serviço atenderá à demanda de seus possíveis clientes. (ALBERONE; CARVALHO; KICORVE, 2012).

A startup é uma organização com a finalidade de inventar novos produtos ou serviços em cenários de alta volatilidade. Esse novo modelo de negócio também exige um novo modelo de gestão, no qual o empreendedor e sua equipe pensam na melhor maneira de atender aos seus atuais e potenciais clientes. O autor afirma a importância de aproveitar toda criatividade dos colaboradores inteligentemente a fim de gerar maior valor para seus clientes (RIES, 2012).

Há décadas o termo startup é utilizado nos Estados Unidos para determinar empresas que trabalham com tecnologia. Contudo, a startup trabalha incessantemente em busca de se tornar repetível e escalável, assim, sua oferta pode se tornar ilimitada, uma vez que o mesmo produto ou serviço pode ser utilizado por diversos clientes. (SERVIÇO BRASILEIRO DE APOIO ÀS MICRO E PEQUENAS EMPRESAS, 2019).

Comparando as startups e as firmas tradicionais, é possível apurar que a capacidade de desenvolvimento é predominante, mas a capacidade transacional também está elencada dentro da estratégia da startup. Tais capacidades podem ser aprimoradas simultaneamente. A capacidade de transacionar se mostra relevante para a adequação do produto no mercado, aceitação do público e caso os resultados apresentados sejam insatisfatórios, rapidamente, se busca uma adaptação. (DULLIUS; SCHAEFFER, 2016).

Para o sucesso de um novo empreendimento não basta apenas um produto ou serviço inovador, é preciso fundamentar-se em estudos para analisar o quão relevante e necessário será o produto ou serviço ofertado. (PELEIAS et al., 2007). Para que a startup se torne viável, ela deve apresentar rapidez e eficiência em relação às carências do público alvo. Para tanto, o modelo de capacidade deve ser adequado de acordo com a realidade cobrada pelo mercado, evitando erros que podem comprometer o seu êxito. (DULLIUS; SCHAEFFER, 2016).

Devido à vertente tecnológica e inovadora das startups, elas cooperam com o desenvolvimento de soluções práticas à sociedade e são fontes importantes de inovação. "O número de startups que está nascendo diante das necessidades da sociedade está crescendo e despejando no mercado uma gama cada vez maior de produtos e serviços" (SILVA, 2014).

De acordo com plataforma Startupbase, existiam 10.279 startups no Brasil em fevereiro de 2019. As cidades que se destacam pelo maior número de startups são: São Paulo, com 2.148 startups, que representa 20,89\% das startups do Brasil; em seguida a cidade do Rio de Janeiro com 613 startups, totalizando 5,96\% das startups brasileiras; e Belo Horizonte é a terceira cidade com o maior número de startups do Brasil, com um total de 449 startups, representando 4,36\% do total de startups. Dentre as startups cadastradas, 7,55\% são do ramo da educação, $3,54 \%$ da área de finanças e 3,39\% do mercado de agronegócio (STARTUPBASE, 2019). 
Segundo Alves (2014), em 2013, São Paulo, Belo Horizonte e Rio de Janeiro eram as três cidades com o maior número de startups do Brasil, com 624, 194 e 170 startups respectivamente. Em comparação a 2019, a mudança foi em relação à colocação das cidades, onde a cidade do Rio de Janeiro passou Belo Horizonte em número de startups e houve um aumento significativo de 2.222 empresas desse tipo, considerando as três cidades.

Este crescimento é importante para a população, uma vez que visa soluções tecnológicas, descomplicadas e rápidas. Contudo, parte dessas empresas encontram dificuldades para seu desenvolvimento no território brasileiro, pois tratando-se de empresas novas, nem sempre possuem capacidade financeira para financiar sua produção e aquisição de insumos necessários. Esta dificuldade se embasa na carga tributária excessiva, custos trabalhistas elevados e baixos incentivos por parte do governo. (NAGAMATSU; BARBOSA; REBECCHI, 2013). Dessa forma, o governo tem grande influência no crescimento e no desenvolvimento de novos empreendimentos em seu país, partindo de uma estrutura simples e adequada favorecendo, assim, o maior número de novas startups e, consequentemente, maior número de inovações (PELEIAS et al., 2007).

Portanto, as dificuldades não se limitam aos cenários macroeconômicos, sendo que a startup passa por diversas dificuldades internas, semelhantes às empresas tradicionais. Ries (2012) aponta que as startups se deparam com determinada complexidade em relação à oferta e demanda, tendo em vista que parte do trabalho da startup é intangível. Sendo assim, o autor ressalta a importância da redução WIP (work-in-proogress) através da mudança do método de produção empurrada (push) para o método de produção puxada (pull). Tal alteração tem como objetivo reduzir o tamanho do estoque e, consequentemente, diminuir os custos da startup.

Apesar de ser um negócio de alto risco e atuar em um ambiente incerto, apresenta também a possibilidade de crescimento acentuado e que, por conseguinte atrai investidores que se interessam pela ideia estabelecida. A modalidade mais conhecida é o investidor-anjo, que são pessoas físicas que aplicam determinado valor em prol da viabilidade do empreendimento.

Para a captação de investimento, a startup, geralmente, passa por um processo de valuation, que avalia a capacidade de geração de inovação e sua relevância, possibilitando que a empresa estabeleça o seu valor de mercado.

O estabelecimento do valor do empreendimento torna mais fácil a tarefa de identificar seus possíveis investidores que, por sua vez, terão uma estimativa do valor da empresa na qual investem. Assim, a startup possui maior possibilidade de encontrar um investidor-anjo para financiar sua operação e, dessa forma, viabilizar sua ascensão no mercado.

\subsection{Modelos de Valuation}

Existem diversos métodos para avaliar o valor do empreendimento, desde modelos mais simples, práticos e objetivos a modelos que são mais subjetivos, refinados e complexos. Vale ressaltar que os modelos mais refinados tendem a ser mais assertivos em seus resultados, sendo assim, quanto maior o nível de detalhamento, maior será a probabilidade de êxito em encontrar o valor justo de determinada organização (MARTINS, 2000).

Devido à diversidade das organizações, o responsável por aplicar a avaliação da empresa deve analisar o método que mais se adequa ao seu modelo de negócio, assim, possibilitando um resultado mais confiável e com menor probabilidade de gerar questionamentos, apesar de ser improvável que estes sejam totalmente evitados. O processo de valuation é uma tarefa complexa que envolve uma gama de variáveis, tangíveis e intangíveis (PEREZ; FAMÁ, 2003). 
Cada modelo de mensuração do valor da empresa tem características próprias e nenhum deles deve ser considerado como infalível, pois trata-se de um processo subjetivo que parte de premissas específicas conforme a metodologia. Ressalta-se que um resultado mais assertivo necessita de que os dados coletados sejam de qualidade e que antes da escolha do método de valuation, o responsável compreenda a estrutura da empresa avaliada (PEREZ; FAMÁ, 2003).

Portanto, o modelo de valuation deve medir as diversas partes que constituem a organização e estimar os componentes intangíveis. De modo geral, o valuation trará alguns benefícios, tais como: identificar as características que possuem maior peso e saber o valor aproximado da empresa para realizar negócios justos (SERVIÇO BRASILEIRO DE APOIO ÀS MICRO E PEQUENAS EMPRESAS, 2017).

Nesta pesquisa, nos deteremos em explanar os modelos apontados por Mielle (2016) como os mais adequados para o valuation de startups.

\subsubsection{Método Berkus}

Para Patterson (2016), esse método de valuation, que foi desenvolvido pelo investidor anjo Dave Berkus, agregou muito valor para os empreendedores. Ele foi criado com o intuito de mensurar o valuation das startups que ainda não possuem faturamento (BERKUS, 2009).

Considerando que algumas metodologias de valuation abrangem apenas os bens tangíveis das organizações, implica em uma grande dificuldade em se medir o valor dos empreendimentos que estão em sua fase inicial, assim sendo, o modelo de Berkus se detém em mensurar o valor dos bens intangíveis das startups (BERKUS, 2009).

O método Berkus apresenta algumas especificidades em sua aplicação, consequentemente, não pode ser utilizado por qualquer startup. Para implementar essa metodologia, é necessário que o empreendimento tenha potencial de faturar 20 milhões de dólares no $5^{\circ}$ ano (BERKUS, 2009). Segundo Salvatella e Huguet (2019), os valores citados por Berkus devem ser adaptados de acordo com a indústria do mercado local.

Este método é baseado nos bens intangíveis das startups, que são a ideia, o protótipo, o time gerencial, relações estratégicas e lançamento ou vendas. Deve-se estabelecer um valor para cada um desses pontos, limitado a 500 mil dólares por critério. Assim, o valor inicial máximo da startup é de 2,5 milhões de dólares (BERKUS, 2009), conforme ilustrado na Tabela 1.

Tabela 1 - Critérios para o método de valuation de Berkus

\begin{tabular}{l|c}
\hline \multicolumn{1}{c|}{ Se existe } & $\begin{array}{c}\text { Adicionar ao valor da } \\
\text { empresa até }\end{array}$ \\
\hline Ideia (valor básico) & US\$ 500 mil \\
Protótipo (tecnologia) & US\$ 500 mil \\
Time gerencial (execução) & US\$ 500 mil \\
Relações estratégicas (mercado) & US\$ 500 mil \\
Lançamento de produtos ou vendas (produção) & US\$ 500 mil \\
\hline
\end{tabular}

Fonte: Elaborado pelo autor

\subsubsection{Método Scorecard}

O método de valuation Scorecard, assim como o modelo de Berkus, mensura o valor dos intangíveis da organização. Tal modelo também é conhecido por método Bill Payne, nome do criador da metodologia que é também um investidor anjo (MIELLE, 2016). 
A avaliação pelo método Scorecard foi formulada com o intuito de explorar o valor não contábil das startups. À vista disso, para utilizá-lo é necessário um valor base para o valuation que será moldado pelos critérios estabelecidos no método Scorecard (PAYNE, 2011). Na Tabela 2 há a ilustração referente aos critérios e pesos pressupostos por Bill Payne:

\begin{tabular}{|c|c|}
\hline Critérios & Peso \\
\hline Força da equipe de gerenciamento & $0-30 \%$ \\
\hline Tamanho da oportunidade & $0-25 \%$ \\
\hline Produto / Tecnologia & $0-15 \%$ \\
\hline Ambiente competitivo & $0-10 \%$ \\
\hline Canais de Marketing / Vendas / Parcerias & $0-10 \%$ \\
\hline Necessidade de investimento adicional & $0-5 \%$ \\
\hline Outros & $0-5 \%$ \\
\hline
\end{tabular}

Fonte: Elaborado pelo autor.

Segundo Payne (2011), para se calcular o valor base do valuation, seguindo o método Scorecard, a startup pode pesquisar no mercado empresas semelhantes, no que tange a localização, área de atuação e maturidade. Posteriormente, devem-se aplicar os critérios e pesos cedidos pelo modelo e comparar com as empresas semelhantes.

\subsubsection{Método da Soma de Fatores de Risco}

De modo geral, tal metodologia de valuation é uma versão atualizada do método de Berkus (MIELLE, 2016). Segundo Payne (2011), esse modelo foi idealizado pela TechAngels de Ohio, empresa que auxilia investidores anjo. A Soma de Fatores de Risco tem como objetivo, assim como os métodos de Berkus e Scorecard, identificar o valor justo da startup considerando que as mesmas não possuem faturamento, por conseguinte, avaliam os valores intangíveis.

Payne (2011) ressalta a inviabilidade de utilizar tal metodologia como um único meio de valuation, considerando que a Soma de Fatores de Risco abrange diversas variáveis e, portanto, possui maior risco. No Quadro 1 estão relacionados os critérios abordados.

Quadro 1 - Critérios para o método da Soma de Fatores de Risco

\begin{tabular}{|l|l|}
\hline \multicolumn{2}{|c|}{ Riscos } \\
\hline Risco de Gerencial & Risco de Competição \\
\hline Estágio do Negócio & Risco de Tecnologia \\
\hline Risco Político / Legislação & Risco de Litígio \\
\hline Risco de Produção & Risco Internacional \\
\hline Risco de Vendas e Marketing & Risco de Reputação \\
\hline Risco de Capital / Financiamento & Potencial de Saída Lucrativa \\
\hline
\end{tabular}

Fonte: Elaborado pelo autor.

Conhecendo os 12 riscos, é necessário adequá-los conforme o método da Soma de Fatores de Risco propõe, atribuindo um peso a cada um para a avaliação, conforme Quadro 2.

Quadro 2 - Pesos para o método Soma de Fatores de Risco

\begin{tabular}{|c|l|}
\hline Pesos & \multicolumn{1}{|c|}{ Descrição } \\
\hline+2 pontos $=500$ mil dólares & Muito positivo para o crescimento da empresa \\
\hline+1 ponto $=250$ mil dólares & Positivo \\
\hline 0 pontos $=$ neutro & Neutro \\
\hline-1 ponto $=-250$ mil dólares & Negativo para o crescimento da empresa \\
\hline-2 pontos $=-500$ mil dólares & Muito negativo \\
\hline
\end{tabular}

Fonte: Elaborado pelo autor. 
Portanto, o valor base da startup deve ser encontrado por meio do valor médio dos empreendimentos do mesmo ramo de atuação, contudo, pode ser uma tarefa difícil encontrar as informações necessárias (MIELLE, 2016).

\subsubsection{Venture Capital}

O método Venture Capital foi idealizado por Bill Sahlman, professor de Harvard, em 1987 (PAYNE, 2011). Tal modelo é estruturado sob a ótica do investidor, tendo como objetivo ponderar o valor presente da startup baseado nas perspectivas de retorno para o investidor. (SALVATELLA; HUGUET, 2019). Esta metodologia de valuation também é utilizada por startups que ainda não possuem receita (PAYNE, 2011).

Essa técnica abrange os conceitos de pre-money, post-money e Retorno Sobre o Investimento - ROI. O conceito pre-money consiste em avaliar a startup antes da rodada de investimento (SALVATELLA; HUGUET, 2019). Sendo assim, utiliza-se a seguinte fórmula:

$$
\text { Valuation pre-money }=\text { Valuation post-money }- \text { Investimento }
$$

O ROI é aplicado nesse método de valuation com a finalidade de mensurar o retorno do investimento em decorrência da retirada do capital investido (SALVATELLA; HUGUET, 2019). Portanto, o ROI é obtido pela fórmula:

$$
\text { ROI }=\text { Valor terminal da startup } \div \text { Valuation post-money }
$$

Entendendo o conceito e o cálculo do valuation pre-money e ROI viabiliza aplicação do cálculo do valuation post-money, que é o valuation após o round de investimento. (SALVATELLA; HUGUET, 2019). Abaixo a fórmula para o cálculo:

$$
\text { Valuation post-money }=\text { Valor terminal da startup } \div \text { ROI }
$$

Segundo Salvatella e Huguet (2019), esse modelo é frágil, tendo em vista que as startups podem receber mais investimentos, por conseguinte, a participação acionária do investidor será diluída. Portanto, vale ressaltar que o investidor deve acompanhar seu investimento e identificar quando retirar ou aportar mais recursos financeiros.

\subsubsection{Avaliação de Fluxo de Caixa Descontado}

A metodologia do Fluxo de Caixa Descontado é o processo de valuation mais utilizado nos dias de hoje e consiste em mensurar o valor presente de uma série de fluxos futuros, com determinada taxa de desconto, em um período estipulado. Portanto, esse modelo auxilia as empresas a identificar os possíveis fluxos de caixa futuros e a probabilidade de ocorrência, dada pela taxa de desconto (SALVATELLA; HUGUET, 2019). O cálculo do valuation da empresa leva em consideração a análise dos fundamentos e perspectivas dos faturamentos, abrangendo os riscos inerentes ao tempo da projeção (REIS, 2017).

Para Mielle (2016), considerando que a empresa apresente certa regularidade mensal do faturamento, é possível aplicar o método do Fluxo de Caixa Descontado. Dessa forma, o valor da empresa será o resultado da soma valor presente dos fluxos de caixa futuros. 
Segundo Reis (2017), para calcular o valuation da empresa por essa metodologia, é necessário entender seus três principais fatores: fluxos de caixa, que são estimativas de faturamento e custos da empresa dentro do período analisado. O valor terminal, ou seja, o valor patrimonial do empreendimento decrescido da depreciação no final da vida útil de cada bem. Por fim, a taxa de desconto que abrange os riscos relacionados ao negócio. Em resumo, o valor da empresa é calculado por meio da seguinte fórmula:

F.C.D. $=\frac{\text { Lucro Líquido }(\text { ano } 1)}{(1+\text { taxa de desconto })^{1}}+\frac{\text { Lucro Líquido }(\text { ano } 2)}{(1+\text { ta de desconto })^{2}}+\cdots+\frac{\text { Lucro Líquido }(\text { ano } n)}{(1+\text { tax de desconto })^{n}}$

\section{METODOLOGIA}

Apesar da existência de vários estudos sobre valuation, poucos relacionam esse tema às startups. Portanto, o presente artigo se adere ao estudo exploratório, abrangendo um tema ainda pouco investigado. A pesquisa exploratória é recomendada para tratar de assuntos poucos abordados, tal tipo de pesquisa utiliza estruturas flexíveis, de modo que o planejamento esteja apto a se adaptar em diversas situações. Esta pesquisa tem como propósito promover novas ideias e uma nova percepção sobre o assunto abordado (CERVO; BERVIAN; SILVA, 2007).

Esta pesquisa é classificada como qualitativa que, segundo Godoy (1995), é uma forma de pesquisa que não se fundamenta em números, mas sim, na análise das situações em seus ambientes, portanto, é útil a descoberta de novas ideias e para a análise e aprimoramento de conhecimentos já existentes. Foram selecionadas três startups que já captaram recursos financeiros externos, por meio de investidor-anjo ou outro, utilizando algum modelo de valuation. Todas estão instaladas na cidade de Belo Horizonte, Minas Gerais. Foram realizadas entrevistas estruturadas, por meio de um roteiro previamente estabelecido. Segundo Marconi e Lakatos (2003), todas as técnicas de coleta de dados possuem vantagens e limitações, sendo que no Quadro 3 estão detalhadas da entrevista.

\section{Quadro 3 - Vantagens e limitações da entrevista}

\begin{tabular}{|l|l|}
\hline \multicolumn{1}{|c|}{ Vantagens } & \multicolumn{1}{|c|}{ Limitações } \\
\hline $\begin{array}{l}\text { Pode ser utilizada com todos os segmentos da } \\
\text { população: analfabetos ou alfabetizados. }\end{array}$ & $\begin{array}{l}\text { Dificuldade de expressão e comunicação de ambas as } \\
\text { partes. }\end{array}$ \\
\hline $\begin{array}{l}\text { Fornece uma amostragem muito melhor da população } \\
\text { geral: o entrevistado não precisa saber ler ou escrever. }\end{array}$ & $\begin{array}{l}\text { Incompreensão, pelo informante, do significado das } \\
\text { perguntas, que pode levar a uma falsa interpretação. }\end{array}$ \\
\hline $\begin{array}{l}\text { Há maior flexibilidade, podendo o entrevistador } \\
\text { repetir ou esclarecer perguntas, formular de maneira } \\
\text { diferente; especificar algum significado, como } \\
\text { garantia de estar sendo compreendido. }\end{array}$ & $\begin{array}{l}\text { Possibilidade de o entrevistado ser influenciado, } \\
\text { consciente ou inconscientemente, pelo questionador, } \\
\text { pelo seu aspecto físico, suas atitudes, ideias, opiniões, } \\
\text { entre outros. }\end{array}$ \\
\hline $\begin{array}{l}\text { Oferece maior oportunidade para avaliar atitudes, } \\
\text { condutas, podendo o entrevistado ser observado no } \\
\text { que diz e como diz: registro de reações, gestos, etc. }\end{array}$ & $\begin{array}{l}\text { Disposição do entrevistado em dar as informações } \\
\text { necessárias. }\end{array}$ \\
\hline $\begin{array}{l}\text { Dá oportunidade para a obtenção de dados que não se } \\
\text { encontram em fontes documentais e que sejam } \\
\text { relevantes e significativos. }\end{array}$ & $\begin{array}{l}\text { Retenção de alguns dados importantes, receando que } \\
\text { sua identidade seja revelada. }\end{array}$ \\
\hline $\begin{array}{l}\text { Há possibilidade de conseguir informações mais } \\
\text { precisas, podendo ser comprovadas, de imediato, as } \\
\text { discordâncias. }\end{array}$ & $\begin{array}{l}\text { Pequeno grau de controle sobre uma situação de coleta } \\
\text { de dados. }\end{array}$ \\
\hline $\begin{array}{l}\text { Permite que os dados sejam quantificados e e } \\
\text { submetidos a tratamento estatístico. }\end{array}$ & Ocupa muito tempo e é difícil de ser realizada. \\
\hline
\end{tabular}

Fonte: adaptado de Marconi e Lakatos (2003, p. 198)

DOI: $10.14211 / x i-e g e p e-118040$ 
Para a seleção dos participantes da entrevista, foram elencados dois pontos primordiais para que as mesmas atendam aos objetivos da pesquisa. O primeiro critério é possuir uma startup em Belo Horizonte que tenha recebido investimento externo e o segundo é ter passado por algum processo de valuation.

Foram convidados a participar das entrevistas quatro proprietários de startups e uma investidora, que poderia dar uma versão do outro lado da negociação de valuation. Entretanto, apenas três proprietários de startups aceitaram o convite e duas entrevistas foram realizadas presencialmente e uma delas por meio de vídeo chamada.

O processo da coleta de dados foi estruturado sob um conjunto de perguntas essenciais para o entendimento e expansão do conhecimento no que tange a história das startups, o financiamento do empreendimento, o modelo do valuation e o resultado do valuation. Com a autorização dos participantes, as entrevistas foram gravadas e, posteriormente, transcritas. No intuito de organizar a pesquisa, foi elaborada uma planilha de dimensões, assim favorecendo o estudo dos dados e facilitando a análise comparativa. Portanto, para a condução da entrevista, foi elaborado um roteiro com as dimensões a seguir:

- História da startup: tópico que tratou o negócio, a origem da ideia e as dificuldades enfrentadas.

- Financiamento do empreendimento: foi abordado o momento da necessidade do aumento de capital, a divulgação da startup aos investidores, a seleção dos investidores, os aspectos do negócio analisados pelos investidores e a negociação do percentual do empreendimento.

- Modelo de valuation: dimensão estruturada com o intuito de identificar o modelo de valuation aplicado, as dificuldades enfrentadas à elaboração do valuation e os parâmetros adotados na elaboração do modelo.

- Resultados do valuation: divisão dedicada aos resultados em comparação aos parâmetros utilizados no valuation, fatores que impactaram os resultados reais do negócio e as perspectivas futuras do empreendimento.

Sendo assim, após o processo da coleta dos dados, organização e tratamento das informações obtidas, foi possível a apresentação e análise dos resultados, mantendo o sigilo dos entrevistados e das respectivas startups.

Os dados foram tratados sob a perspectiva da análise de conteúdo, que segundo Mozzato e Grzybovski (2011), são técnicas de análise das comunicações textuais que possuem processos sistemáticos, com o intuito de esclarecer os indicadores qualitativos ou quantitativos. Segundo os autores, a metodologia consiste em três etapas: a pré-análise, exploração do material e o tratamento dos resultados, inferência e interpretação. Mozzato e Grzybovski (2011) apontam a importância de tal modelo e ressaltam que o mesmo pode ser utilizado de maneira individual ou em conjunto com outras técnicas e se mostra vantajosa no que tange a comparabilidade dos dados obtidos. Portanto, elucidam a importância da análise contextualizada, para que, assim, os resultados sejam coerentes e assertivos de acordo com objeto de estudo.

\section{APRESENTAÇÃO E ANÁLISE DOS RESULTADOS}

Para melhor compreensão e para a imersão, no que tange startups, valuation e o ecossistema como um todo, a pesquisa de campo foi estruturada com um instrumento de coleta de dados, que consistiu em um roteiro de perguntas relevantes ao estudo. 
O primeiro empreendedor entrevistado relatou sobre suas duas startups. O seu primeiro negócio nasceu entre 2012 e 2013 , sendo que a startup presta serviços à mobilidade urbana, com enfoque em estacionamento rotativo e atua em 6 munícipios. A sua segunda startup foi criada de 2013 para 2014 e atua no ramo de recarga, semelhante à uma moeda eletrônica, com o intuito de atender ao público que não possui vínculo com bancos e financeiras e, consequentemente, não utilizam cartões de débito e crédito. Ambas já receberam aportes financeiros, tendo em vista que os dois primeiros aportes foram realizados pelos próprios sócios, já o próximo será algo mais elaborado e ele almeja $\mathrm{R} \$ 5$ milhões para cada startup.

O segundo entrevistado também possui duas startups, sendo a primeira voltada para aluguéis de automóveis que surgiu em 2016 com o propósito de intermediar o proprietário de um automóvel e um locatário. A segunda startup foi criada entre 2017 e 2018, classificada como fintech e nasce em colaboração com o primeiro empreendimento, uma vez que a empresa fornece plano para investidores de tal forma que os recursos arrecadados são utilizados para reinvestimento em ambas startups. A primeira startup recebeu seu primeiro investimento em um processo de pré aceleração e, até a data da entrevista, não havia recebido outros aportes.

O terceiro entrevistado é proprietário de uma startup fundada em 2016 com proposta de auxiliar empresas na contratação de funcionários por meio de uma plataforma online. A startup recebeu seu primeiro aporte em um processo de pré aceleração semelhante à do entrevistado 2 , posteriormente recebeu investimento de um de seus clientes e, de acordo com o empreendedor, estão trabalhando em um valuation para a terceira captação de recursos financeiros.

Munidos das questões, foram realizadas as entrevistas, nas quais foram abordadas as seguintes dimensões: história da startup, financiamento do empreendimento, modelo de valuation e resultados do valuation.

\subsection{História da Startup}

Para o entrevistado 1, as suas duas startups surgiram após doze anos trabalhados em uma empresa de telefonia, até que um dia surgiu a ideia de que se o usuário podia recarregar o celular, qualquer coisa pode ser carregada. Portanto, o desejo de empreender falou mais alto e o mesmo solicitou a sua demissão dois anos após o surgimento da ideia. Como ele mesmo disse, "a maior dificuldade é sair da inércia", mas também elencou as principais atrações: o primeiro produto, o ambiente ainda não muito inerente à inovação, o tempo necessário para o desenvolvimento da plataforma, a ausência de dados comparativos e as dificuldades em conseguir recursos financeiros.

O entrevistado 2 já possuía um empreendimento junto com um sócio e identificaram uma nova oportunidade de mercado, venderam a empresa e investiram no novo negócio em 2016. Com o surgimento da ideia dessa startup, desenvolveram também um negócio paralelo que funciona em cooperação com o primeiro. As dificuldades encontradas por eles foram relacionadas à logística entre a locação de um veículo e o empréstimo a um terceiro, pois segundo o entrevistado, eles precisam ter carros próprios para maior autonomia e velocidade para trocar peças, manutenções preventivas e outras. Disse também da necessidade dos carros reservas para possíveis eventualidades, o que gera mais custos para a startup. Outra dificuldade está relacionada ao próprio cliente, uma vez que o mesmo não conserva o carro, deteriorandoo rapidamente. Para evitarem tal situação aplicam um filtro para selecionar seus clientes.

De maneira semelhante ao entrevistado 1, o entrevistado 3 também teve a ideia de sua startup dentro da empresa onde trabalhava, mas a sua startup opera em um setor diferente. 
Então ele ressaltou a importância do seu perfil arrojado e possuir uma boa rede de networking na área de tecnologia. Com o passar do tempo, identificou grande dificuldade enfrentada por determinado setor e ali enxergou as dificuldades do cliente que seu futuro empreendimento atuaria. Embora a ideia surgira dentro da organização onde trabalhava, a startup ganha forma em um programa de inovação de sua universidade. No decorrer do desenvolvimento da empresa, o entrevistado 3 destacou as maiores dificuldades encontradas, que foram: burocracia, alta carga tributária, falta de conhecimento do empreendedor, falta de apoio do mercado por não ser maduro em relação à inovação e tecnologia, barreiras para testar alguns modelos e o próprio público brasileiro que, segundo ele, não tem uma mentalidade alinhada à disrupção.

Dessa forma, verifica-se que todas as ideias de negócio surgiram a partir de uma oportunidade identificada pelos empreendedores, observa-se que todas startups analisadas passaram por dificuldades, uma vez que, em se tratando de um negócio inovador, encontraram alguns obstáculos até a consolidação do empreendimento.

\subsection{Financiamento do Empreendimento}

O entrevistado 1 disse que o investimento inicial foi realizado pelos próprios sócios, que já o conheciam e sabiam do seu desenvolvimento profissional, segundo ele, "é difícil captar dinheiro no mercado com apenas uma ideia e um PowerPoint". Esse processo de captação de recursos financeiros é uma jornada de negociações, em que é apresentada a ideia para o investidor, demonstrando as métricas e, por fim, é necessário estipular as metas, pois a startup ainda não possuí um histórico. Contudo, o entrevistado afirma que, assim que os números projetados são alcançados, o investidor convida para uma reunião e começa uma nova negociação. Em seu empreendimento, parte do aporte inicial foi dividido em econômico e financeiro. Até realizaram um valuation inicial para a startup 1, uma vez que o negócio estava em nível de maturação maior quando o projeto do investidor veio à eles, mas ressalta que no final das contas virou uma negociação na qual pautaram em que o investidor poderia ajudar e o quanto estava disposto a aportar, de tal forma que ambas as partes teriam ganhos.

Em relação à startup 2, o proprietário e o investidor planejaram uma reunião e negociaram o valor que precisavam para dar continuidade no negócio, seguindo a ideia de benefício mútuo para ambas as partes. O empreendedor ressaltou a importância de fazer boas negociações, de modo que não entreguem grande percentual da startup.

Para o entrevistado 2, a percepção de uma necessidade de aumento de capital para a organização ocorreu quando houve uma grande demanda de trabalho e poucas pessoas para executá-lo, tendo em vista que todo empreendimento era desenvolvido por três pessoas. Sendo assim, o primeiro investimento foi direcionado ao aumento da equipe. De acordo com o empreendedor, a ideia foi apresentada para mais de trinta pessoas e o aspecto com maior peso para o investidor que aceitou a proposta foi a equipe. Também ressaltou a importância de um produto formado, um negócio que já possua algum faturamento, que tenha uma boa margem de retorno, além da equipe. Por fim, concluiu que a negociação com o investidor foi com base na perspectiva da equipe e a projeção financeira.

De acordo com o entrevistado 3, a necessidade de recursos financeiros é percebida a partir do momento que a empresa tem planos ambiciosos e focados em crescimento e não em pagar contas. Ele fala da importância de entender que os empreendimentos não precisam captar investimentos para validar um modelo e que os investimentos não devem ser utilizados para pagar contas. Falou da importância da família com apoio financeiro no início de sua trajetória, 
quando passou por dificuldades. Da mesma forma que o entrevistado 2, a startup passou por um processo no qual apresentou o pitch para vários investidores e de lá saiu o primeiro round de investimento. Segundo o entrevistado 3, o mercado em que ele está inserido está muito aquecido e os investidores foram atrás deles por meio de clientes que eles atendiam, inclusive, um presidente de um grupo que eles atendem aportou recursos financeiros enquanto pessoa física, por causa da excelência do trabalho prestado. E para um terceiro round, o empreendedor informou que já estudaram um fundo de investimentos e que tem sido mais detalhado do que os aportes anteriores. Mencionou a importância de os empreendedores não leiloarem as suas empresas, mas sim identificar o investidor que tenha os mesmos princípios e valores da organização. Em concordância com os demais entrevistados, disse que os investidores analisam a equipe, o fundador e acrescentou o mercado, o potencial de crescimento da startup e a tecnologia envolvida.

Percebe-se que a necessidade do aumento do capital ocorre quando há maior demanda pelo produto ou serviço da startup, uma vez que a estrutura estabelecida não suporta a demanda dos clientes. Os empreendedores ressaltaram a importância da negociação com os investidores, de modo que seja benéfico para ambos. Vale ressaltar as falas do terceiro entrevistado, em que o mesmo pontua a importância de não buscar investimentos para pagar contas.

\subsection{Modelo de Valuation}

Para o entrevistado 1, o valuation é um tema bem complexo, no que tange startups, como ele mesmo disse, "quanto mais no início você está, mais complexo vai ser". Mencionou o método Fluxo de Caixa Descontado e disse que o mercado ainda o utiliza, mas a grande diferença está na taxa mínima de atratividade que, devido ao alto risco de se investir em uma empresa nascente, a exigência de retorno fica em torno de $35 \%$ ao ano. Pontuou a dificuldade em encontrar empresas semelhantes para comparar e ponderar o cálculo de suas projeções. $\mathrm{O}$ empreendedor citou outros modelos de valuation, tais como: modelo de Kepler, Múltiplos, Berkus e Barclays. Contudo, alegou a dificuldade da aplicação do Múltiplos em relação a sua necessidade de comparação com outras empresas e demonstrou pouco conhecimento sobre os métodos de Barclays e Berkus. Informou também que passaram por processos em diferentes instituições de investimentos, sendo que em um pediram as projeções financeiras e a outra se deteve ao valor intangível.

O entrevistado 2 seguiu por um caminho semelhante ao entrevistado 1, em que o mesmo estimou a projeção financeira com base comparativa a partir de estatísticas, pois não possuem muitas informações do seu mercado. Contudo, o primeiro valuation da empresa seguiu a lógica do processo de pré aceleração que passaram para conseguir o primeiro investimento. Percebese que o entrevistado demonstrou pouco conhecimento no quesito valuation e disse que a projeção do método Fluxo de Caixa Descontado está desorganizada.

Em concordância com o entrevistado 1, o entrevistado 3 conseguiu os primeiros investimentos por meio de negociações boca a boca, no qual sentava com os possíveis investidores da sua startup e falava da necessidade de recursos e eles falavam o quanto estavam dispostos a investir e, no decorrer das conversas, chegavam a um consenso. Portanto, não houve a utilização de nenhuma técnica formal de valuation, mas sim negociação com base no que cada parte envolvida acreditava valer a empresa.

O empreendedor ressalta as dificuldades encontradas de se medir o valor da startup, tendo em vista ao grande valor intangível da organização e seu potencial de crescimento 
exponencial. Assim, o mesmo apontou que para cada estágio da startup deve-se aplicar determinado processo de valuation. Disse que devido ao histórico de sua startup, é mais fácil se chegar a um valuation, que não é o caso das startups em fases iniciais, e como estão em busca de um terceiro round de investimento, que envolve um maior volume de recursos financeiros, contrataram uma instituição para realizar o valuation mais fundamentado de sua startup. Essa instituição que medirá o valor da empresa, segundo o empreendedor, está acompanhando o desenvolvimento da startup, buscando entender o potencial de crescimento e utilizaram as rodadas anteriores de investimentos em comparação às projeções. Portanto, o entrevistado 3 ressalta que cada fase da startup possui um modelo especifico, que os investidores colocam maior peso no fundador e mercado, e também pontua a importância de se mensurar o intangível do empreendimento no processo de valuation.

Observa-se que há certa limitação no conhecimento dos entrevistados sobre os métodos de valuation e sobre a adequação ao modelo de negócio das startups. Sendo assim, os empreendedores enfatizam a negociação informal junto aos investidores e a importância da rede de networking. Segundo os entrevistados, as dificuldades encontradas à aplicação do valuation, tendo em vista que as startups em estágio inicial, são a falta de um histórico de faturamento, o modelo de negócio ser de difícil comparação e apresentar grande peso em quesitos intangíveis.

\subsection{Resultados do Valuation}

Segundo o entrevistado 1, alguns parâmetros do valuation foram alcançados. Ele disse que devido às mudanças do cenário, algumas metas ficaram aquém e outras além da realidade. Contudo, está com boas perspectivas para os próximos anos, tanto em relação ao mercado, quanto em relação ao desenvolvimento de sua startup. Disse que o desafio para os próximos anos é entregar um produto com maior qualidade e diversificar seu ramo de atuação.

O entrevistado 2 afirma que ultrapassaram um pouco a projeção, contudo estão com algumas dificuldades, tais como gastos superiores aos previstos, a logística do negócio e algumas situações econômicas do país. O empreendedor pretende abrir mais empresas e diversificar a sua atuação e criar startups interligadas, em que uma preste serviço para a outra, barateando os seus custos e criando uma holding que apresente sinergia entre as companhias.

Já o entrevistado 3 afirma que as primeiras projeções deram errado, mas a partir do segundo aporte, já foi mais estruturado e tiveram um resultado aproximado. Para ele, os cálculos não se confirmaram devido à pouca maturidade do mercado, o modelo estava inválido e foram apenas cálculos sem uma base concreta. O proprietário possuí perspectivas de crescimento do faturamento para o próximo ano de até $30 \%$ e vão trabalhar em cima dessa perspectiva.

Conforme informado pelos entrevistados, o resultado do valuation não foi condizente à proporção alcançada pelas startups. Segundo os entrevistados, o resultado do valuation não foi atingido devido ao cenário do país, à maturidade do mercado e por não possuir uma base concreta à projeção. Todos empreendedores possuem boas perspectivas para o futuro da startup, inclusive o entrevistado 1 e 2 possuem planos de expansão para atuarem em outros mercados.

\section{CONSIDERAÇÕES FINAIS}

O presente estudo analisou os processos de valuation pelos quais passaram algumas startups de Belo Horizonte. Portanto, a pesquisa foi fundamentada nos conceitos da teoria e a prática por meio de entrevistas com proprietários de startups. 
A partir da análise dos dados, constata-se que todos empreendedores já possuíam uma ocupação e as ideias surgiram a partir de oportunidades identificadas por eles. Percebe-se que todos enfrentaram dificuldades, sendo as principais: burocracia, falta de conhecimento, falta de apoio do mercado, falta de aderência à inovação e tecnologia demonstrada pelas leis e pelos próprios brasileiros, demora de alguns processos logísticos, altas cargas tributárias, sair da inércia, dificuldade de conseguir recursos financeiros e ausência de dados comparativos.

Embora as startups passem por diversas dificuldades, a falta de conhecimento é a que merece maior atenção, uma vez que os empreendedores utilizaram metodologias que não se mostraram aderentes ao negócio, assim, relataram as discrepâncias entre os resultados projetado e alcançado. Como citou o entrevistado 1, o Fluxo de Caixa Descontado é o mais conhecido e utilizado pelos empreendedores, contudo, o entrevistado 3 menciona a importância de entender o estágio da startup e utilizar o modelo de valuation mais adequado para cada fase.

Com base nos dados coletados, os empreendedores ressaltaram que os aspectos mais analisados pelos investidores ao selecionarem uma startup para aportar recursos financeiros são bens intangíveis, tais como: equipe, tecnologia e mercado. Dessa forma, pode-se dizer que o método Fluxo de Caixa Descontado apresenta limitações para mensurar o valor das startups.

Considerando que startups são empresas nascentes que desenvolvem produtos ou serviços inovadores, com potencial de crescimento exponencial, pode-se dizer que cada startup merece seus devidos cuidados e ajustes no processo de valuation. Os empreendedores relataram a dificuldade de encontrar no mercado dados suficientes para uma análise comparativa e as startups não seguem os mesmos padrões de valuation de empresas tradicionais, tendo em vista que grande parte de seu valor é intangível.

Os dados obtidos neste estudo possibilitaram elencar as principais dificuldades enfrentadas pelos empreendedores entrevistados em relação ao valuation, em que se destacaram a falta de conhecimento de ferramentas mais aderentes aos seus negócios e as limitações dos modelos utilizados. Dessa forma, foi possível confrontar as técnicas citadas pela teoria com as práticas das startups e as necessidades de ajustes de acordo com o modelo de negócio.

Assim, o presente estudo apresenta as principais metodologias de valuation, que embora existam várias, há necessidade de averiguar qual é a mais adequada para cada empresa. Aponta que o modelo mais conhecido pelos entrevistados foi o método Fluxo de Caixa Descontado, apresenta as principais dificuldades enfrentadas pelos empreendedores e as principais características analisadas pelos investidores.

Contudo, vale ressaltar as principais limitações e dificuldades encontradas no decorrer da pesquisa. As dificuldades passaram desde o momento de contatar os proprietários, o agendamento das entrevistas e a qualidade das informações obtidas para a elaboração do trabalho, pois foi perceptível o pouco conhecimento sobre o valuation por parte dos proprietários. Além disso, a quantidade de empreendedores e investidores que se disponibilizaram a participar da pesquisa foi muito pequena.

Considerando o resultado da pesquisa e suas limitações, em outras oportunidades sugere-se o estudo com empreendedores de outras localidades, o uso do modelo quantitativo ou qualitativo com dimensões distintas e também entrevista com os investidores de startups para obter um desfecho comparativo. Assim, o estudo de valuation para startups ganha maior abrangência e traz diferentes percepções que contribuirão para uma estrutura consolidada do conhecimento sobre valuation. 


\section{REFERÊNCIAS}

ASSOCIAÇÃO BRASILEIRA DE STARTUPS. Manual sobre conceitos, metodologias e investimentos em startups. Disponível em: http://www.abstartups.com.br/. Acesso em: 04 abr. 2018.

ALBERONE, M.; CARVALHO, R.; KIRCOVE, B. Sua ideia ainda não vale nada: o guia prático para começar a validar seu negócio. Disponível em: http://s-inova.ucdb.br//. Acesso em: 28 mar. 2018.

ALVES, Fábia Santos. Um estudo das startups no Brasil. Disponível em: http://repositorio.ufba.br/ri/handle/ri/15395. Acesso em: 23 fev. 2019.

BERKUS, Dave. The Berkus Method - Valuing the Early Stage Investment. Disponível em: https://berkonomics.com/?p=131. Acesso em: 05 mar. 2019.

CERVO, Amado Luiz; BERVIAN, Pedro Alcino; SILVA, Roberto da. Metodologia científica. 6. ed. São Paulo: Pearson Prentice Hall, 2007.

DULLIUS, A. C.; SCHAEFFER, P. R. As Capacidades de Inovação em Startups:

Contribuições para uma Trajetória de Crescimento. Revista Alcance, v. 23, n. 1, p. 34-50, 2016.

GODOY, Arlida Schmidt. Introdução à pesquisa qualitativa e suas possibilidades. Rev.

Adm.empres., São Paulo, v 35, n. 2, p. 57-63, Apr. 1995. Disponível em:

https://www.scielo.br/scielo.php?script=sci_arttext\&pid=S0034-

75901995000208\&Ing=en\&nrm=iso. Acesso em: 05 abr. 2019.

MARCONI, M. de A.; LAKATOS, E. M. Fundamentos de metodologia científica. 5. Ed. São Paulo: Atlas, 2003.

MARTINS, Eliseu. Avaliação de empresas: da mensuração contábil à econômica. Cad. estud., São Paulo, n. 24, p. 28-37. dec. 2000. Disponível em:

http://www.scielo.br/scielo.php?script=sci_arttext\&pid=S1413-

92512000000200002\&lng=en\&nrm=iso. Acesso em: 05 abr. 2018.

MIELLE, Raphael. Valuation para Startups - 9 Metódos Explicados. Disponível em: https://medium.com/@raphaelmielletrintinalia/valuation-para-startups-9-metódos-explicados2349207df552. Acesso em: 06 mar. 2019.

MOZZATO, A. R.; GRZYBOVSKI, D. Análise de conteúdo como técnica de análise de dados qualitativos no campo da Administração: potencial e desafios. Revista de Administração Contemporânea, v. 15, n.4, p. 731-747, 2011.

NAGAMATSU, F. A; BARBOSA, J e REBECCHI, A. Business Model Generation e as contribuições na abertura de startups. Disponível em:

http://repositorio.uninove.br/xmlui/bitstream/handle/123456789/556/659-1192-1-RV\%20-

\%20business\%20model\%20generation.pdf?sequence=1. Acesso em: 07 abr. 2018. 
PATTERSON, Adam. Startup Finance 101: Está precificando ou valorando sua startup? Disponível em: https://startupi.com.br/2016/12/startup-finance-101-esta-precificando-ouvalorando-sua-startup/. Acesso em: 05 mar. 2019.

PAYNE, Bill. Valuations 101: Scorecard Valuation Methodology. Disponível em: blog.gust.com/valuations-101-scorecard-valuation-methodology/. Acesso em: 06 mar. 2019

PAYNE, Bill. Valuations 101: The Venture Capital Method. Disponível em: blog.gust.com/valuations-101-the-venture-capital-method/. Acesso em: 08 mar. 2019.

PAYNE, Bill. Valuations 101: The Risk Factor Summation Method. Disponível em: blog.gust.com/valuations-101-the-risk-factor-summation-method/. Acesso em: 07 mar. 2019.

PELEIAS, I. R.; SILVA, A. J. M.; GUIMARÃES, I. C.; MACHADO, L. S.; SEGRETI, J. B. O empreendedorismo e a evolução econômica das nações: idéias e conceitos para seu sucesso no Brasil. Revista de Negócios, v. 12, n. 2, p. 18-33, 2007.

PEREZ, Marcelo Monteiro; FAMÁ, Rubens. Avaliação de Empresas e Apuração de Haveres em Processos Judiciais: uma análise segundo a Teoria de Finanças. Disponível em: http://sistema.semead.com.br. Acesso em: 01 abr. 2018.

RIES, Eric. A startup enxuta: como os empreendedores atuais utilizam a inovação contínua para criar empresas extremamente bem-sucedidas. São Paulo: Lua de Papel, 2012.

REIS, Tiago. Fluxo de Caixa Descontado: Uma estimativa de análise futura de uma empresa. Disponível em: https://www.sunoresearch.com.br/artigos/fluxo-de-caixadescontado/. Acesso em: 09 mar. 2019.

SALVATELLA, Josep; HUGUET, Laia. Modelos de valoración de startups. Disponível em: https://rocasalvatella.com. Acesso em: 05 mar. 2019.

SERVIÇO BRASILEIRO DE APOIO ÀS MICRO E PEQUENAS EMPRESAS. Conheça o valuation e saiba quanto vale sua empresa. Disponível em:

www.sebrae.com.br/sites/PortalSebrae/artigos/conheca-o-valuation-e-saiba-quanto-vale-suaempresa,290732f8d0cbf410VgnVCM1000004c00210aRCRD. Acesso em: 17 fev. 2019.

SERVIÇO BRASILEIRO DE APOIO ÀS MICRO E PEQUENAS EMPRESAS. O que é uma startup? Disponível em: www.sebrae.com.br/sites/PortalSebrae/sebraeaz/o-que-e-umastartup,616913074c0a3410VgnVCM1000003b74010aRCRD. Acesso em: 17 fev. 2019.

SILVA, J. A. L. Abrir uma startup não é tão fácil como parece. Disponível em: https://www.infomoney.com.br/negocios/startups/noticia/3506090/abrir-uma-startup-nao-taofacil-como-parece-acabam-fechando. Acesso em: 06 abr. 2018.

STARTUPBASE. Estatísticas. Disponível em: https://startupbase.abstartup.com.br/stats. Acesso em: 25 fev. 2019. 